\title{
Anatomic variations of the extrathoracic course of the intercostobrachial nerve and its clinical significance
}

\author{
Soubhagya Ranjan Nayak', Smita Singh Banerjee ${ }^{2}$ \\ ${ }^{1}$ Associate Professor, ${ }^{2}$ Assistant Professor, Department of Anatomy, College of Medicine \& J.N.M. Hospital, WBUHS, \\ Kalyani, Nadia, West Bengal-741235, India
}

Background: The intercostobrachial nerve (ICBN) can present anatomic alterations in its course, but in general it originates as a lateral branch of the second intercostal nerve and penetrates the axilla, in the mid axillary line. Its communication with brachial plexus (BP) is of clinical importance. Neurotization and nerve grafting procedures have renewed interest in the communications of peripheral nerves, like that of between BP and ICBN. Aims and Objective: The current study was conducted with an aim to observe the variation in the origin of extra thoracic course of the ICBN and its connection with the components of BP. Materials and Methods: One hundred thirty hemi-thoraxes of 65 adult cadavers (35male $\& 30$ female) of Indian origin were dissected. After removal of the skin and superficial fascia, the ICBN was identified from its origin. The point of emergence from the intercostal space and its communication with BP was noted and photographed. Results: Extrathoracically, ICBN originated from the $2^{\text {nd }}$ intercostals space in $100 \%$ specimens. Additionally ICBN originated from the $1^{\text {st }}$ intercostals space in $3.8 \%$ specimens, from $3^{\text {rd }}$ intercostals space in $20.7 \%$ cases. The ICBN communicated more frequently with medial cutaneous nerve of the $\operatorname{arm}(\mathrm{MCN})$ in $63 \%$ cases and with other BP branches in $44.6 \%$ cases. Conclusion: In the present study we observed ICBN and BP are coherently linked anatomically. The anatomical knowledge of ICBN origin and its variable communication with BP branchesis significant in the event of surgical treatment of breast cancers, lymph node clearance, anaesthetic nerve blocks and traction injuries to the brachial plexus.

Key words: Intercostobrachial nerve; Mastectomy; Medial cutaneous nerve; Brachial plexus

\section{INTRODUCTION}

Intercostobrachial nerve (ICBN) can present anatomic alterations in itscourse, but in general it originates as a lateral branch ofthe second intercostal nerve (T2) and, when perforating the anterior and intercostal serratus muscles, it penetrates theaxilla at approximately $1-2 \mathrm{~cm}$ before the track of the long thoracic nerve, in the mid axillary line. After passingthrough the base of the axilla, it is divided in two or threebranches until it reaches the medial side of the superiorpart of the arm and axilla. ${ }^{1}$ Axillary dissection during breast carcinoma surgeries poses risksto ICBN from stretching as well asfrom frank transaction. So it becomes necessary to have a sound knowledge of its anatomical variations. $^{2}$

Damage to ICBN is a common complication ofaxillary node dissection during mastectomy. The medial portion of ICBN is encountered during exposureof the long thoracic and thoracodorsal nerves. Identification of this nerve is therefore essential to its preservation..$^{3-5}$ According to Toressan et al. (2003), preservation of ICBN is feasible and leads to a significantdecrease in the alteration of pain sensitivity ofthe arm without interfering with the total time ofthe surgery, the number of dissected nodes or localrelapse rates. ${ }^{6}$ 
Loukas et al. (2007) reported that ICBN usually carries a $\mathrm{T} 2$ contribution to the brachial plexus and its preservation increases with the knowledge of its union with various branches of brachial plexus. Furthermore they opined, damage to this nerve may thereforehave additional consequences beyond the deficitsdescribed for the axillary and pectoral regions. For example, if the T2 communication containedmotor fibers, there could be some degree of weaknessassociated with its transaction. ${ }^{7}$

In the present study we carried out dissection in the axilla of 65 adult cadavers of both sexes to determine the anatomical variations in the origin of the ICBN and its communication with medial cutaneous nerve of arm (MCN) and medial cord of brachial plexus (BP).

\section{MATERIALS AND METHODS}

The ICBN was examined in 65 adult cadavers of Indian origin. Of these, 35 were male and 30 were female and ranged in age from 56 to 83 years; mean age of 67. All the cadavers were fixedin formalin-phenol-alcohol solution. None of the cadaversrevealed any evidence of previous surgical proceduresor traumatic lesions to the axillary regions. After removal of the skin and superficial fascia around the axilla, the ICBN was identified from its origin. The point of emergence from the intercostal space and its communication with BP branches were noted and photographed.

\section{RESULTS}

\section{Occurrence rate and source of ICBN}

Among the 130 axilla ( 35 male \& 30 female) dissected, there were $130(100 \%)$ cases we observed ICBN originated from the second intercostal nerve (T2) (Figure 1). In addition to the former; In 5 cases $(3.8 \%)$ ICBN originated from the first intercostal nerve (T1) (Figure 2) and in 27 cases (20.7\%) ICBN originated from the third intercostal nerve (T3) (Figure 3) (Table 1).Among 130 cases, there were 98 cases of single trunk (Fig.1), 24 cases of double trunks (Figure 3) and in 8 cases of multiple trunks (Figure 2) were observed.

\section{DISTRIBUTION OF ICBN}

After originating from the respective intercostal spaces the ICBN mainly supplied the skin of the posteromedial aspect of the arm, bottom of the axilla and nearby thoracic walls (Figure 4). Five cases ICBN originated from T1 in combination with T2 or T3 roots or both (Figure 2). In 45 cases multiple nerve roots of ICBN originated

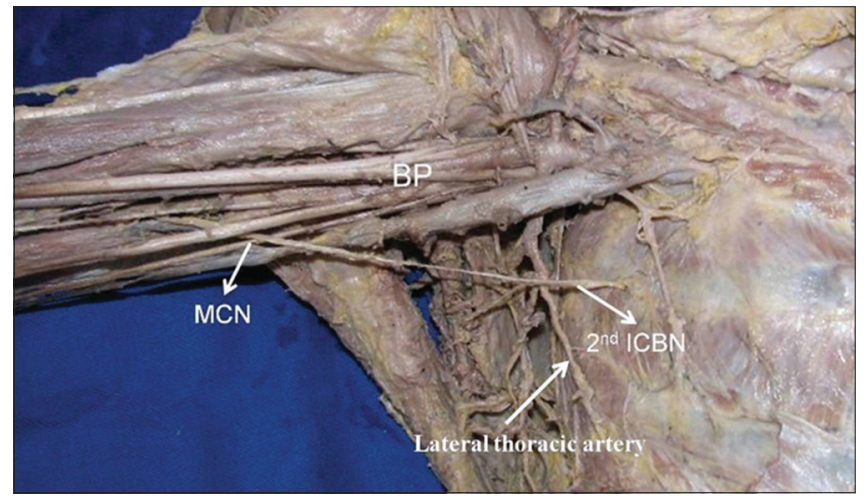

Figure1: Right side axilla and upper thoracic region of a male cadaver showing the emergence of intercostobrachial nerve (ICBN) from the second intercostal space (T2). $2^{\text {nd }}$ ICBN- ICBN originating from T2, $\mathrm{BP}$ - brachial plexus, MCN- medial cutaneous nerve of arm

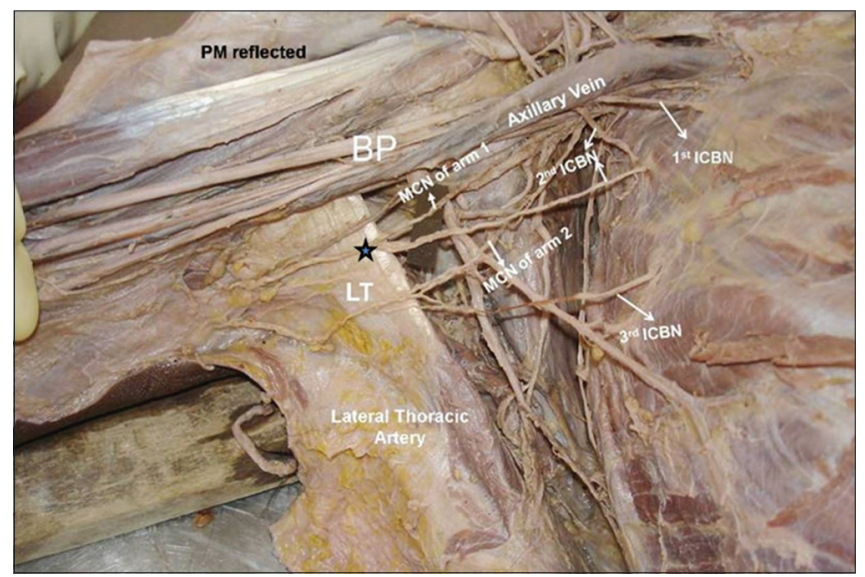

Figure 2: Right side axilla and upper thoracic region of a female cadaver showing emergence of intercostobrachial nerve (ICBN) from $1^{\text {st }}(\mathrm{T} 1), 2^{\text {nd }}(\mathrm{T} 2)$ and $3^{\text {rd }}(\mathrm{T} 3)$ intercostal nerve respectively. Note the double roots of the T2 and its communication (five point star) with the medial cutaneous nerve of arm (MCN). There are two MCN (MCN of arm 1- upper MCN, MCN of arm 2- lower MCN). BP- brachia plexus, LT- latissimusdorsi muscle

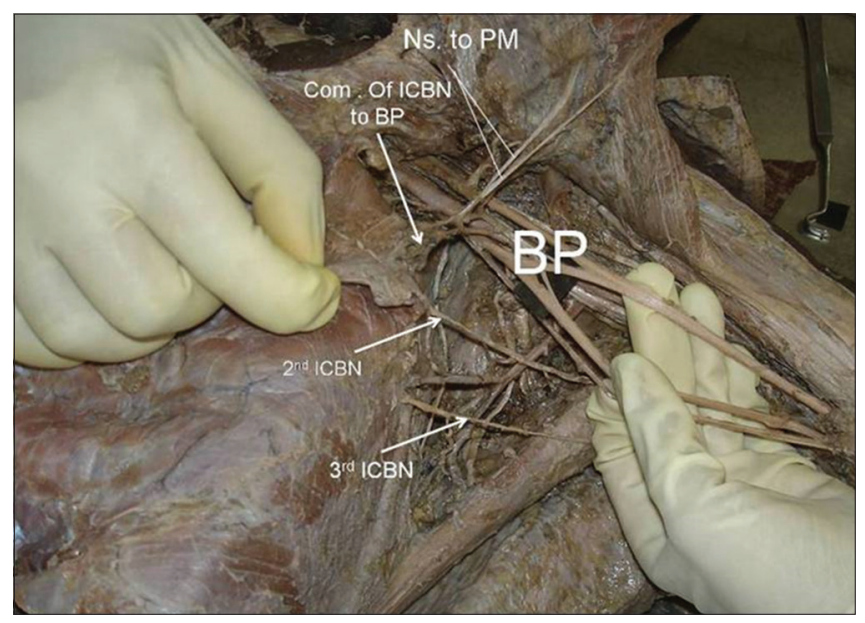

Figure 3: Left side axilla and upper thoracic region of a male cadaver showing emergence of ICBN from the $2^{\text {nd }}$ intercostal space $\left(2^{\text {nd }} I C B N\right)$ and from the $3^{\text {rd }}$ intercostal space ( $3^{\text {rd }}$ ICBN). Note the communication (Com) of ICBN with brachial plexus (BP) and emergence of nerves (Ns), which innervates pectoralis major muscle (PM) 
and supplied to the medial side of arm along with the MCN (Figure 5) and in 7 cases the branches from ICBN, innervated pectoralis major muscle (Fig 3, 4). ICBN was found to be attached with the MCN in 82 cases (63\%) and

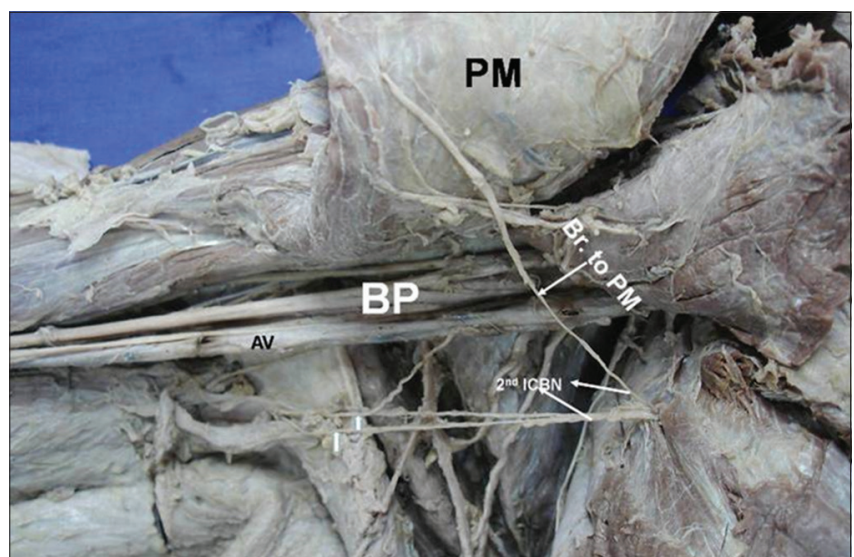

Figure 4: Right side axilla and upper thoracic region of a female cadaver showing multiple roots of the $2^{\text {nd }}$ ICBN [upper thick root branch (Br.) to pectoralis major muscle (PM), lower thin roots (white arrows) supplying the skin of the posteromedial aspect of the arm, bottom of the axilla and $\mathrm{MCN}]$. AV- axillary vein, BP- brachial plexus

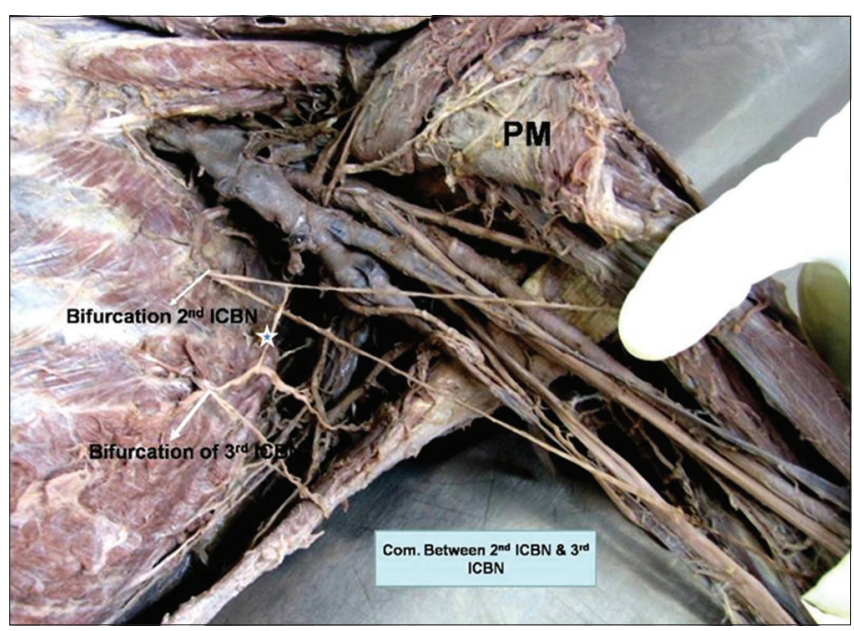

Figure 5:Left side axilla and upper thoracic region of a male cadaver showing emergence of ICBN from the $2^{\text {nd }}$ intercostal space ( $\left.2^{\text {nd }} I C B N\right)$ and from the $3^{\text {rd }}$ intercostal space $\left(3^{\text {rd }} I C B N\right)$ with multiple roots and communication between T2 and T3 (five point star). PM- pectoralis major with the medial cord BP in 58 cases (44.6\%) (Figure 2, 3) (Table 1).

\section{DISCUSSION}

The lateral cutaneous branch of the T2 divides into a thinner or absent anterior branch and a thicker posterior branch that is generally considered as the ICBN ${ }^{8}$. In rare conditions, the ICBN combines with the lateral cutaneous branch of the first and/or intercostal nerve'. Zhu et al. (2014) observed ICBN was present in $97.4 \%$ cases and absent in $2.5 \%$ populations they studied ${ }^{10}$. Similar to our finding, Loukas et al. (2007) reported ICBN was observed in $100 \%$ subjects they studied ${ }^{\circ}$.

Anilkumar P (2014) reported that one ICBN on each side in 29 cadavers $(72.5 \%)$, then two ICBN on each side in 8 cadavers (20\%), then three ICBN on each side in 2 cadavers $(5 \%)$ and Five ICBN on each side in 1 cadaver $(2.5 \%)$ out of the 40 cadavers they dissected. They also observed that the ICBN was having connections to the BP on each side in 11 cases $(27.5 \%)^{11}$. In the present study we observed ICBN communicated with MCN in 82 cases $(63 \%)$ and ICBN communicated with BP in 58 cases (44.6\%). Loukas et al. (2007) observed ICBN had a 100\% communication with the BP9. Loukas et al. (2007) also observed ICBN communicated with the medial cord of $\mathrm{BP}$ in $35.6 \%$ cases and with MCN in 25.5\% ${ }^{9}$. O'Rourke et al. (1999) reported that ICBN communicated either with BP or MCN in 15 out of 28 dissections $(53.5 \%)^{12}$.

Zhu et al. (2014) reported a single trunk of the ICBN that originated from the T2 accounted for 120 cases, 23 cases of double trunks and 9 cases of multiple trunks out of 152 surgeries ${ }^{11}$. In present study we observed 98 cases $(75.3 \%)$ of single trunks, 24 cases $(18.4 \%)$ of double trunks and in 8 cases $(6.1 \%)$ multiple trunks respectively out of 130 cases. Benton et al. (2014) observed approximately $80 \%$ cases the T1 had no lateral cutaneous branch, but they reported $30 \%$ cases ICBN originated from the $\mathrm{T} 3^{13}$.

\begin{tabular}{|c|c|c|c|c|c|}
\hline \multirow{3}{*}{$\begin{array}{l}\text { Source of ICBN arising from the intercostal space } \\
\text { and its communication to medial cutaneous } \\
\text { nerve of arm (MCN) and brachial plexus (BP) }\end{array}$} & \multirow[b]{3}{*}{ Total } & \multicolumn{4}{|c|}{ Total number of axilla dissected (130) } \\
\hline & & \multicolumn{2}{|c|}{ Male (70) } & \multicolumn{2}{|c|}{ Female (60) } \\
\hline & & $\begin{array}{c}\text { Right } \\
\text { side (35) }\end{array}$ & $\begin{array}{c}\text { Left } \\
\text { side (35) }\end{array}$ & $\begin{array}{c}\text { Right } \\
\text { side (30) }\end{array}$ & $\begin{array}{c}\text { Left } \\
\text { side (30) }\end{array}$ \\
\hline Source of ICBN arising from the $\mathrm{T} 1$ & $5(3.8 \%)$ & $2(5.7 \%)$ & 0 & $2(6.6 \%)$ & $1(3.3 \%)$ \\
\hline Source of ICBN arising from the $\mathrm{T} 2$ & $130(100 \%)$ & $35(100 \%)$ & $35(100 \%)$ & $30(100 \%)$ & $30(100 \%)$ \\
\hline Source of ICBN arising from the T3 & $27(20.7 \%)$ & $5(14.2 \%)$ & $7(20 \%)$ & $8(26.6 \%)$ & $7(23.3 \%)$ \\
\hline Communication of ICBN with MCN & $82(63 \%)$ & $17(48.5 \%)$ & $24(68.5 \%)$ & $22(73.3 \%)$ & $19(63.3 \%)$ \\
\hline Communication of ICBN with BP & $58(44.6 \%)$ & $12(34.2 \%)$ & $18(51.4 \%)$ & $15(50 \%)$ & $13(43.3 \%)$ \\
\hline
\end{tabular}


In the present study we observed the ICBN originated from the $\mathrm{T} 3$ in $20.7 \%$ cases, in comparison to the $30 \%$ cases reported by Benton et al. (2014) ${ }^{13}$. Further, we observed ICBN originated in 3.8\% cases from the T1 and 100\% cases from the $\mathrm{T} 2$ respectively.

Loukas etal. (2010) mentioned that the knowledge and variation of T2 contributions to the brachial plexus is significant in the event of surgical treatment of breast cancers, lymph node clearance, anaesthetic nerve blocks, avulsionand traction injuries to the brachial plexus ${ }^{14}$. Loukas et al. (2007) reported an unusual union between ICBN and medial pectoral nerve and opined that potential muscular and sensory innervations may be derived from the above mentioned variant ${ }^{15}$. Loukas et al. (2006) reported a variation in which, ICBN gave rise to a medial pectoral branch, which partially innervated both the pectoralis minor and pectoralis major muscles ${ }^{16}$. In the present study we observed ICBN gave a motor branch to pectoralis major muscle in 7 out of 130 cases. Above observations strengthens the current trend of preservation of ICBN during axillary surgical procedures ${ }^{6,16}$.

\section{CONCLUSION}

ICBN origin and its communication with the brachial plexus varies a great deal among various literature reported till date, this may happen due to the studies carried out among various ethnic group and population size. Present study indicates the potential variations of ICBN and its communication to the BP, which is both sensory and motor in nature. The knowledge obtained from the present study can be utilized in mastectomy and axillary surgeries to preserve the ICBN and its various communicating branches for proper risk management post surgery and also to protect the sensory and motor loses.

\section{ACKNOWLEDGEMENTS}

The authors of the present study would like to convey their deep sense of gratitude to all teaching and non-teaching staff members of the respective department for the help presented while carrying out the study.

\section{REFERENCES}

1. Temple WJ and Ketcham AS. Preservation of the intercostobrachial nerve during axillary dissection for breast cancer. Am J Surg 1985; 150: 585-588.

2. Balkund KS and Priyadharshini S. A study on variations of intercostobrachial nerve. MedPulse -Int J of Anat 2017; 4: 14-16.

3. Abdullah TI, Iddon J, Barr L, Baildam $A D$ and Bundred NJ. Prospective randomized controlled trial of preservation of the intercostobrachial nerve during axillary node clearance for breast cancer. Br J Surg 1998; 85: 1443-1445.

4. Baker RJ, Fischer JE (eds). Segmental mastectomy and axillary dissection. In: Mastery of surgery. Vol. $1 / 4^{\text {th }}$ Ed. Lippincott, Williams and Wilkins, Philadelphia. 2001; pp. 591-593.

5. Bratschi HU and Haller U. Significance of the interocostobrachial nerve in axillary lymph node excision. Geburt shilfe Frauen heilkd 1990; 50: 689-693.

6. Torresan RZ, Cabello C, Conde DM and Brenelli HB. Impact of the preservation of the intercostobrachial nerve in axillary lymphadenectomy due to breast cancer. Breast J 2003; 9: 389-392.

7. Louis RGM and Wartmann C. T2 Contributions to the brachial Plexus. Neurosurgery 2007; 60: 13-18.

8. Cunnick GH, Upponi $S$ and Wishart GC. Anatomical variants of the intercostobrachial nerve encountered during axillary dissection. Breast 2001; 10: 160-162.

9. Loukas M, Hullett J, Louis RG, Holdman S and Holdman D. The gross anatomy of the extrathoracic course of the intercostobrachial nerve. Clin Anat 2006; 19: 106-111.

10. Zhu JJ, Liu XF, Zhang PL, Yang JZ, Wang J, Qin Y, et al. Anatomical information for intercostobrachial nerve preservation in axillary lymph node dissection for breast cancer. Genetics and Molecular Res 2014; 13; 9315-9323.

11. Kumar PA, Reddy DRK and Bapuji P. Multiple Intercostobrachial Nerves. J of Evol Med and Dent Sci 2014; 57: 12978- 12983.

12. O'Rourke MG, Tang TS, Allison SI and Wood W. The anatomy of the extrathoracicintercostobrachial nerve. Aust NZ J Surg 1999; 69:860-864.

13. Benton MJ, Schlairet MC and Gibson DR. Change in quality of life among breast cancer survivors after resistance training: is there an effect of age? J Aging Phys Act 2014; 22: 178-185.

14. Loukas M, El-Zammar D, Tubbs RS, Apaydin N, Louis RG, Wartman C, et al., A review of the T2 segment of the brachial plexus. Singapore Med J 2010; 51: 464-467.

15. Loukas M, Grabska J, Tubbs RS and Louis RG. An unusual union of the intercostobrachial nerve and the medial pectoral nerve. Folia Morphol 2007; 66: 356-359.

16. Loukas M, Louis RG, Fogg QA, Halner B and Gupta AA. An unusual innervation of pectoralis minor and major muscles from a branch of the intercostobrachial nerve. Clin Anat 2006; 19: 347-349.

\footnotetext{
Authors Contribution:

SRN- Concept and design of the study, review of literature, data collection; SSB- Manuscript preparation, table preparation and critical revision of the manuscript.

Work Attributed to: Study was conducted in the Department of Anatomy, College of Medicine \& J.N.M. Hospital, WBUHS, Kalyani, W.B., India and Department of Anatomy, Centre for Basic Sciences, Kasturba Medical College, Bejai, Mangaluru 575004, Karnataka, India.

Orcid ID:

Dr. Soubhagya Ranjan Nayak - (D) https://orcid.org/0000-0002-3591-2363

Dr. Smita Singh Banerjee - (i) https://orcid.org/0000-0003-2115-196X

Source of Support: Nil, Conflict of Interest: None declared.
} 